\title{
KESEHATAN MENTAL REMAJA PUTRI KORBAN PERCERAIAN ORANG TUA
}

\author{
${ }^{1}$ Erlina Harahap, ${ }^{2}$ Sukatno, ${ }^{3}$ Auliya Warzuqni, ${ }^{4}$ Nor Mita Ika Saputri \\ ${ }_{1,2,3}$ Prodi Bimbingan dan Konseling, FKIP Universitas Muhammadiyah Tapanuli Selatan \\ erlina.harahap@um-tapsel.ac.id
}

\begin{abstract}
Divorce does not only have an impact on those concerned (husband and wife) but also involves children, especially young women and is a separate burden for children so that it has an impact on their mentality. The purpose of this study was to determine the mental health of adolescent girls who were victims of parental divorce. The research method uses descriptive qualitative data collection techniques with interviews, observations and documentation. The results showed that 1) the cause of divorce in Kasik Putih Village, Sungai Aur District, West Pasaman Regency was caused by economic factors, infidelity that spread to other things such as domestic violence (domestic violence). 2) Mental health disorders experienced by teenage girls who are divorced victims such as feelings of revenge, anger also violates their parents, sadness and self-blame, feelings of dislike, loss of security and warmth, and aggressive behavior. 3) the impact after their parents divorced, their lives fell apart, they felt disappointed and destroyed, the most profound of which was dropping out of school, not being enthusiastic about going to school and feeling inferior when they were with friends. The conclusions that can be drawn from the results of this study are guidance. This family counseling guidance is an interactive process to help families in achieving a balance where every family feels happy. Themselves when facing problems and change their views to be more positive and increase good and positive activities for themselves and life and always and get closer to the creator, namely Allah SWT.
\end{abstract}

Keywords: Divorce, Mental Health, Young Women

\begin{abstract}
Abstrak: Perceraian tidak hanya berdampak bagi yang bersangkutan (suami-istri) namun juga melibatkan anak khususnya remaja putri dan beban tersendiri bagi anak sehingga berdampak pada mentalnya. Tujuan penelitian ini untuk mengetahui kesehatan mental remaja putri korban perceraian orang tua. Metode penelitian menggunakan kualitatif deskriptif teknik pengumpulan data dengan wawancara, observasi dan dokumentasi. Hasil penelitian menunjukkan bahwa 1) penyebab perceraian di Desa Kasik Putih Kecamatan Sungai Aur Kabupaten Pasaman Barat disebabkan oleh faktor ekonomi, perselingkuhan yang merambat kepada hal-hal yang lain seperti kekerasan dalam rumah tangga (kdrt). 2) Gangguan kesehatan mental yang di alami oleh remaja putri korban perceraian seperti perasaan dendam, marah juga menyalahi orang tuanya, sedih juga menyalahkan diri sendiri, perasaan tidak disukai, kehilangan rasa aman dan kehangatan, dan bersikap agresif. 3) dampak setelah orang tua bercerai hidupnya berantakan merasa kecewa dan hancur yang paling mendalam adalah putus sekolah tidak bersemangat dalam bersekolah dan merasa minder bila bersama teman-teman. Kesimpulan yang dapat di ambil dari hasil penelitian ini bimbingan. Bimbingan konseling keluarga ini merupakan suatu proses interaktif untuk membantu keluarga dalam mencapai keseimbangan dimana setiap keluarga merasakan kebahagiaan. Konseling keluarga dapat dijadikan salah satu cara atau solusi bijak mengatasi dan memberi solusi dalam permasalah keluarga dan pada dasarnya dapat menekan dan meminimalisir terjadinya gangguan kesehatan mental pada remaja putri korban perceraian. Bagi remaja putri, diharapkan agar mampu mengendalikan diri saat mengahadapi masalah dan merubah pandangan agar lebih positif dan memperbanyak kegiatan-kegiatan yang baik dan positif untuk diri dan kehidupan serta selalu dan mendekatkan diri kepada sang pencipta yaitu Allah SWT.
\end{abstract}

Kata kunci: Perceraian, Kesehatan Mental, Remaja Putri 



\section{PENDAHULUAN}

Keluarga merupakan lingkungan yang sangat erat kaitannya dengan perkembangan diri anak (Kagan, 1999; Mackay, 2005; Wenar dan Kerig, 2006). Secara ideal perkembangan anak dan remaja akan optimal apabila mereka bersama keluarga yang harmonis sehingga berbagai kebutuhan yang diperlukan dapat terpenuhi (Wenar dan kerig, 2006). Penyebabnya perceraian beberapa faktor yang mempengaruhi diantaranya masalah ekonomi, kekerasan dalam rumah tangga, campur tangan orang tua, tidak ada tanggung jawab, perpindahan agama, kurangnya komunikasi, dan adanya orang ketiga. Permasalahan mengenai perceraian diperkuat dengan data semakin banyaknya perceraian yang terjadi tahun ke tahun di indonesia. Kesehatan mental menunjukan suatu perubahan kepribadian seseorang yang berkaitan dengan mental baik normal maupun abnormal dan mencangkup beberapa aspek seperti rasionalitas, stabilitas emosional, sosiabilitas, temperamen, karakter dan sikap, secara kesehatan mental remaja khususnya remaja putri yang kedua orang tuanya bercerai mengalami resiko terhadap tumbuh kembang mentalnya. Hal-hal yang biasa ditemukan pada remaja putri ketika orang tuanya bercerai adalah rasa tidak aman, menyalahkan diri sendiri, sedih, marah, dan kesepian.

Remaja putri mengalami gangguan kesehatan mental lebih besar dari remaja lakilaki karena penyebabnya, perempuan dari segi hormon lebih cepat mengalami pematangan ketimbang laki-laki. Kemudian karena fase-fase pematangan tersebut, sehingga perempuan lebih dulu terkena dampak perubahan yang terjadi seperti pubertas, dimana banyak terjadi gejolakgejolak emosional dan pada umumnya remaja putri lebih banyak menghabiskan waktu dirumah dan jika ada masalah lebih cenderung menyendiri sehingga dapat memungkinkan kesehatan mentalnya terganggu ketimbang remaja laki-laki yang lebih suka bergaul, banyak menghabiskan waktu diluar rumah bersama teman-temannya melakukan hal-hal yang bisa menenangkan dirinya.

Hasil penelitian sebelumnya oleh Putri Erika Ramadani ${ }^{1}$ dan Dra. Hj.Hetty Krisnani, $\mathrm{M} . \mathrm{Si}^{2}$ di dalam jurnalnya yang berjudul "Analisis Dampak Perceraian Orang Tua Terhadap Anak Remaja" menunjukkan bahwa dampak perceraian dapat memberikan dampak buruk bagi anak baik fisik maupun psikologis anak, sehingga perceraian memang perlu dipertimbangkan matang-matang, dan orang tua harus bisa memberikan pengertian yang baik pada anak untuk mengurangi dan mengatasi dampak buruk yang terjadi pada perceraian. Karena perceraian akan melibatkan anak khususnya yang memasuki usia remaja, perceraian merupakan beban tersendiri bagi anak sehingga berdampak pada psikisnya. Data di KUA di tahun 2020 di Desa Kasik Putih, Kecamatan Sungai Aur, Kabupaten Pasaman Barat terdapat 15 kasus perceraian dan 5 kasus perceraian yang korbannya remaja putri. Perceraian tersebut sangat memperihatinkan karena berdampak pada kesehatan mental. 
Berdasarkan uraian diatas maka peneliti tinggal bersama dengan korban. Sedangkan tertarik untuk mengadakan penelitian dengan analisis data menggunakan reduksi data, display judul “ Kesehatan Mental Remaja Putri Korban data ( penyajian data) dan penarikan Perceraian Orang Tua di Desa Kasik Putih, kesimpulan.

Kecamatan Sungai Aur, Kabupaten Pasaman Barat “

\section{HASIL}

Hasil observasi, wawancara dan

\section{METODE}

Sugiyono (2008:46) metode adalah suatu cara yang digunakan untuk mencapai tujuan yang telah ditetapkan. Pada penelitian ini digunakan jenis penelitian kualitatif dengan metode deskriptif. Sugiyono (2013:15) metode penelitian kualitatif adalah penelitian yang berlandaskan pada filsafat post positivisme, digunakan untuk meneliti pada kondisi obyek yang alamiah, sebagai lawannya adalah eksperimen dimana peneliti adalah sebagai instrumen kunci, pengambilan sumber data dilakukan secara purposive dan snowbaal, teknik pengumpulan dengan triangulasi (gabungan), analisis data bersifat induktif/kualitatif, dan hasil penelitian kualitatif lebih menekankan makna dari pada generalisasi. cara menentukan sampel diatas, maka dalam penelitian ini peneliti menggunakan cara nonprobability sampling dengan teknik purposive sampling yaitu pengambilan sampel sumber data dengan pertimbangan atau kriteria sebagai berikut: 1) remaja putri usia 12-18 tahun 2) remaja putri korban perceraian 3) dan tinggal dengan orang tua tunggal. Dengan demikian peneliti menetapkan responden penelitian sebanyak tiga orang. Adapun informan penelitian ini adalah adalah ibu kandung korban atau ayah kandung yang dokumentasi dan analisa temuan yang ada dan menguraikannya ke bentuk deskriftif adapun temuan pada remaja putri yang mengalami gangguan kesehatan mental akibat dari perceraian orang tua yaitu: perasaan dendam, marah dan menyalahi orang tua, sedih dan menyalahkan diri sendiri, perasaan tidak disukai, kehilangan rasa aman dan hilangnya keramahan dan kehangatan dan bersikap agresif.

\section{PEMBAHASAN}

Berdasarkan hasil temuan dan analisa data beberapa hal tentang perceraian dan menjadi fatal bagi kesehatan mental remaja putri. beberapa faktor yang menyebabkan orang tua bercerai, hasil penelitian menunjukkan bahwa ada beberapa terjadinya perceraian di Desa Kasik Putih Kecamatan Sungai Aur Kabupaten Pasaman Barat yaitu faktor ekonomi, perselingkuhan dan kekerasan dalam rumah tangga (KDRT). Masalah tersebut yang akhirnya memunculkan masalah-masalah yang lain. Masalah yang dihadapi setelah orang tua bercerai. tidak mendapat kasih sayang dari seorang ayah lagi dan merindukan saat-saat bersama ayah. Upaya mengatasi kekecewaan pada remaja putri korban perceraian dengan cara mengatasi kekecewaan sesuai dengan 
keinginan yang bisa membat remaja lega. SIMPULAN

Kebiasaan yang muncul setelah orangtua bercerai adalah lebih suka menghabiskan waktu bersama teman-temannya dan malas pulang kerumah mencari kesibukan di luar rumah. Upaya dalam menyikapi perceraian orang tua menyikapi perceraian orang tua ini masih dengan perasan kecewa dan belum menerima kalau orang tuanya bercerai. Tekanan kesehatan mental remaja putri korban perceraian kehilangan rasa aman dan kehangatan dan bersikap agresif.

Dampak dari perceraian orang tua yang sering terjadi berkurangnya minat remaja dalam pendidikan yang menunjukkan penurunan drastis dalam prestasi dan nilai sekolah. Hal ini secara signifikan menghalangi kemampuan remaja belajar disekolah sehingga pendidikan menghambat proses karir remaja. Menurut responden NA bahwa cita-citanya terhalang karena perceraian orang tua dan tidak mau menyusahkan ibunya untuk menyekolahkannya sampai perguruan tinggi, sedangkan menurut responden FS sangat berpengaruh pada karirnya karena sejak Sekolah Dasar sudah putus dan merasa bahwa hidupnya sudah tidak jelas dan malas untuk memikirkan masa depannya. Dampak setelah orang tua bercerai bahwa dirasakannya adalah hidupnya berantakan merasa kecewa dan hancur sedangkan menurut responden FS bahwa dampak dari perceraian orang tuanya adalah yang paling mendalam adalah putus sekolah dan responden KGP merasakan dampak orang tua bercerai adalah tidak bersemangat dalam bersekolah dan merasa minder bila bersama teman-teman.
Kesehatan mental remaja putri korban perceraian orang tua tidak dapat ditinggalkan begitu saja, berbagai permasalahan negatif yang melatar belakangi masalah tersebut terjadi didalam sebuah keluarga. kesehatan mental sama pentingnya dengan kesehatan fisik, apalagi ditemukan adanya kaitan antara gangguan fisik yang berpengaruh terhadap mental atau sebaliknya gangguan mental yang berpengaruh terhadap gangguan kondisi fisik.

Bagi remaja putri, diharapkan agar mampu mengendalikan diri saat mengahadapi masalah dan merubah pandang agar lebih positif dan memperbanyak kegiatan-kegiatan yang dapat memberi pengaruh yang baik untuk diri dan kehidupan serta selalu dan mendekatkan diri kepada sang pencipta yaitu Allah SWT. Perceraian orang tua dapat menjadi pengalaman yang sangat buruk bagi remaja mereka akan merasakan atmosfer keluarga yang berbeda dan remaja akan merasakan kehilangan karena keluarga merupakan lingkungan yang sangat erat kaitannya dengan pembentukan diri anak tidak hanya berdampak bagi yang bersangkutan (suami-isteri) namun juga melibatkan anak khususnya yang memasuki usia remaja.

Dampak perceraian seperti yang sudah disampaikan sebelumnya akan berpengaruh pada kesehatan mental remaja putri, yang akhirnya akan berpengaruh pula pada tindakan dan perilaku remaja. Oleh karena itu dibutuhkan cara agar masalah perceraian orang tua tidak begitu membebani anak-anak mereka. Salah satu caranya adalah dengan memaksimalkan layanan konseling keluarga. 


Bimbingan konseling keluarga ini
memfokuskan pada masalah-masalah
berhubungan dengan situasi keluarga dan
penyelenggaraannya melibatkan anggota
keluarga. Bimbingan konseling keluarga ini
merupakan suatu proses interaktif untuk
membantu keluarga dalam mencapai
keseimbangan dimana setiap keluarga
merasakan kebahagiaan. Bimbingan konseling
keluarga dapat dijadikan salah satu cara
mengatasi dan memberi solusi dalam
permasalah keluarga, dan pada dasarnya dapat
menekan dan meminimalisir terjadinya
gangguan kesehatan mental pada remaja putri
korban perceraian.

\section{DAFTAR RUJUKAN}

Agustina Nurhayati, 2011. Pernikahan dalam perspektif al-qur'an. Asas, volume 3 nomor 1 : halaman 99-101.

Aqib Zainal, 2013. Konseling kesehatan mental. Bandung: Yrama Widya.

Ardian Prapmojati, 2018. Dinamika psikologis remaja korban perceraian, sebuah studi kasus kenakalan remaja. Jurnal ilmu perilaku manusia, volume 2 nomor 1: halaman 1-14.

Basri, Hasan. 1996 Remaja Berkualitas, Proplematika Remaja Dan Solusinya. Yogyakarta: Pustaka Pelajar.

Gunarsa, Singgah D. 1986. Dampak Perceraian Orang Tua Terhadap Psikologis Remaja. Professional Islam, Vol 2 No2: halaman 100.

Ida Untari, dkk, 2018. Dampak perceraian orang tua terhadap psikologis remaja. Profesional islam, Vol 2 No 2: halaman 100.
Kartono Kartini, 2014. Patologi sosial II kenakalan remaja. Jakarta: PT Rajagrafindo Persada.

Putri Erika Ramadhani, 2019. Analisis dampak perceraian orang tua terhadap anak remaja. Jurnal pekerja sosial, volume 2 nomor 1: halaman 112-115.

Reski yulina widiastuti, 2016. Dampak perceraian pada perkembangan sosial dan emosional anak usia 5-6 tahun, volume 2 nomor 2: halaman 77-79.

Sarwono Sarlito, 2014. Psikologi remaja . Jakarta : Rajawali Pers.

Sri Widya Haryanie, Dkk, 2012. Dampak perceraian orang tua terhadap emosi anak. Halaman 105-106.

Sudarso, 2008. Kenakalan Remaja. Jakarta : PT Reneka cipta.

Sugiyono, 2003. Motode penelitian administrasi. Bandung : CV Alfabeta.

Yusuf LN, Syamsu. Psikologi Perkembangan Anak Dan Remaja. Bandung: PT Remaja Rosdakarya. 